\title{
Effect of Chest Physical Therapy Modalities on Oxygen Saturation and Partial Pressure of Arterial Oxygen in Mechanically Ventilated Patients
}

\author{
Maged A. Meawad ${ }^{1}$, Akram Abd El Aziz ${ }^{1}$, Hany E. Obaya ${ }^{1}$, Sabah A. Mohamed ${ }^{2}$, and Khaled Mohamed \\ Mounir $^{3}$ \\ Departments of ${ }^{1}$ Physical Therapy for Cardiovascular/Respiratory Disorder \& Geriatrics and ${ }^{2}$ Chest Medicine, Cairo \\ University, Department of ${ }^{3}$ Physical Therapy for Cardiopulmonary\& Geriatrics Disorders, Egyptian Chinese \\ University, Egypt \\ Correspondence: Maged A. Meawad, E-mail: magedptdr@gmail.com, Mobile: 00201007977226
}

\begin{abstract}
Background: Chest physical therapy plays an important role in increasing $\mathrm{Pao} 2$ and $\mathrm{SaO} 2$ among ICU patients which is considered as a good indicator for the general improvement of the patient besides decreasing ICU staying and costs.

Purpose: To figure out the effect of chest physical therapy on oxygen saturation and partial pressure of arterial oxygen.

Patients and Method: Thirty patients post MV, their age ranged from 50 to 60 years old were recruited in this study. The patients were selected from ICUs of Kasr al Ainy hospital, Faculty of Medicine, Cairo University. The patients received chest physiotherapy (percussion, vibration, manual hyperinflation), positioning and upper and lower limbs exercises.

Results: Increase in $\mathrm{Pao} 2$ and $\mathrm{SaO} 2$ in addition to decreased incidence of chest infection and decreased ICU stay.

Conclusion: The results of this study support the importance of chest physiotherapy on increasing $\mathrm{SaO} 2$ and Pao2, decrease ICU duration and decrease health care costs.
\end{abstract}

Keywords: chest physiotherapy, partial pressure of arterial oxygen (Pao2), oxygen saturation (SaO2) and Mechanical ventilation (MV).

\section{INTRODUCTION}

Intensive Care Units (ICUs) are special units used to provide care for critically ill patients. ICU is expensive to operate; consuming 15-40\% of total hospital costs ${ }^{(1)}$.

MV is always a lifesaving intervention, but carries many potential complications including pneumothorax, lunginjury, alveolar damage, and ventilator-associated pneumonia ${ }^{(2)}$.

Chest physiotherapy is one such common preventive strategy where chest physiotherapists routinely treat most of the ICU patients with various chest physiotherapy techniques such as Manual hyperinflation, suctioning, patient positioning, chest vibrations, chest percussions, various coughing techniques in combination or individually to prevent pulmonary complications in the ICUs ${ }^{(3) .}$

Chest physiotherapy procedure help to reinflate the collapsed lobe of a lung, Positioning combined with chest percussion, as well as lung hyperinflation plus suction, are the best ways to quickly solve lung lobe atelectasis ${ }^{(4)}$.

Percussion and vibration and shaking methods are based on the assumption that applying an external force to the chest wall to loosen the mucus facilitates airway mobilization and clearance, it involves rhythmical beating with properly shaped hands on the chest wall over specific regions of the lungs and removing the mucus ${ }^{(5)}$.
Chest wall percussion and vibration were used by up to $80 \%$ of physiotherapists, often in combination with manual hyperinflation.This technique involves the production of large and small oscillatory movements performed during expiration that aim to increase expiratory flow and subsequent pulmonary secretion clearance ${ }^{(6)}$.

Mobilization refers to physical activity sufficient to elicit acute physiological effects that improve ventilation, central and peripheral perfusion, circulation, muscle metabolism and alertness and countermeasures for venous stasis and deep vein thrombosis ${ }^{(7)}$.

Positioning can be used to increase gravitational stress and associated fluid shifts, through head tilt and other positions that approximate the upright position, That increases lung volumes and gas exchange, stimulates autonomic activity, and can reduce cardiac stress from compression ${ }^{(8)}$.

Passive movement has been shown to enhance ventilation in neurological patients in high-dependency units ${ }^{(9)}$.

Is one of a number of techniques which provides a greater than baseline tidal volume to the lungs. It is frequently used by physiotherapists in the treatment of intubated mechanically ventilated patients with the aim of increasing alveolar oxygenation, recruiting atelectasis or mobilizing pulmonary secretions ${ }^{(6)}$.

Aim of the study: was to evaluate the efficacy of chest physical therapy modalities on $\mathrm{SaO} 2$ and $\mathrm{Pao} 2$. 


\section{PATIENT AND METHODS}

Randomized study and thirty patients recently mechanically ventilated, randomly selected, their age ranged from 50 to 60 years old were recruited in this study. The patients were selected from ICU Kasr al Ainy hospital, Faculty of Medicine, Cairo University, during the period between June 2016 and April 2017. The patients received chest physiotherapy (percussion, vibration, suctioning, manual hyperinflation), positioning and upper and lower limbs exercise.

Ethical statement: The patients or their relatives were approached to ask if they would be willing to engage in the research. The study was approved by the Ethics Board of Cairo University.

Approval statement: The participants signed on a consent form.

Inclusion criteria: All patients from the first day of being mechanically ventilated between the age of 50 to 60 years old

Exclusion criteria: All patients had the following criteria were excluded: Patients younger than 50 and older than 60 years, on NIMV, Acute pulmonary edema, untreated pneumothorax and open heart surgeries, admission with tracheostomy

\section{Methods:}

Monitoring: ECG and Heart rate. Oxygen saturation: by pulse oximetry. Respiratory rate.

Laboratory investigation: ABG: for measurement of Pao2.

Procedures: The procedure was done during the first 3 days of patient admission in ICU. Each patient was given 2 sessions every day. Each session lasted for 30 minutes.

\section{Treatment procedures:}

The program was designed as follows, [1]. Percussion: Was done for 5 minutes performed manually (using cupped hands) by clapping the chest wall over of the lung [2]. Chest vibrations: Was done for 5 minutes all over the lung from distal to proximal and from lateral to medial direction. [3]. Manual hyperinflation: The waveform consisted of an inspiration of three seconds, sustained inspiration for 2 seconds, and a fast release of the valve to ensure a short expiration, during which bag was held compressed. Expiration was passive and unobstructed to facilitate expiratory flow [4]. Limb exercises: In the form of passive or active assisted movement for the 4 limbs ( 2 sets for each limb and each set 10 repetitions) for 15 minutes.
Limb exercises (passive, active assisted or active) were performed according to patient's status. [5]. Suctioning: Duration of endotracheal suctioning was limited to $15 \mathrm{sec}$ [6]. Positioning: At the end of the treatment session and after suctioning, the head end was arranged to be positioned at an angle of elevation in the range of 30-45.

\section{Statistical analysis:}

Student t-test conducted for comparison between pre and post treatment mean values of $\mathrm{PaO} 2$ and $\mathrm{Sao} 2$. The level of significance for all statistical tests was set at $p<0.05$. All statistical measures were performed through the statistical package for social studies (SPSS) version 19 for windows.

\section{RESULTS}

There were an increase in $\mathrm{PaO} 2$ and $\mathrm{SaO} 2$.

Table (1): Comparison between pre-treatment and post-treatment mean value of the variables.

\begin{tabular}{|c|c|c|c|c|c|c|c|}
\hline \multirow{2}{*}{$\begin{array}{l}\text { Partial } \\
\text { pressure } \\
(\mathbf{m m H g})\end{array}$} & Pre & Post & \multirow{2}{*}{ MD } & \multirow{2}{*}{$\begin{array}{c}\% \text { of } \\
\text { change }\end{array}$} & \multirow{2}{*}{ F-value } & \multirow{2}{*}{ p-value } & \multirow{2}{*}{ Sig } \\
\hline & $\overline{\mathrm{X}}_{ \pm \mathrm{SD}}$ & $\overline{\mathrm{X}}_{ \pm \mathrm{SD}}$ & & & & & \\
\hline $\mathrm{PaO} 2$ & $76.33 \pm 11.83$ & $82.13 \pm 9.74$ & -5.8 & 7.59 & 5.85 & 0.02 & $\mathrm{~S}$ \\
\hline $\mathrm{SaO} 2(\%)$ & $89.63 \pm 3.36$ & $96.96 \pm 3.4$ & -7.33 & 8.17 & 192.8 & 0.0001 & $S$ \\
\hline \multirow{2}{*}{$\begin{array}{l}\bar{X} \\
\text { SD }\end{array}$} & \multirow[t]{2}{*}{ : Mean } & MD & \multicolumn{2}{|c|}{$\begin{array}{l}\text { : Mean } \\
\text { difference }\end{array}$} & $\mathrm{p}$ value & \multicolumn{2}{|c|}{$\begin{array}{l}\text { : Probability } \\
\text { value }\end{array}$} \\
\hline & & $\mathrm{s}$ & \multicolumn{2}{|c|}{ : Significant } & & & \\
\hline
\end{tabular}

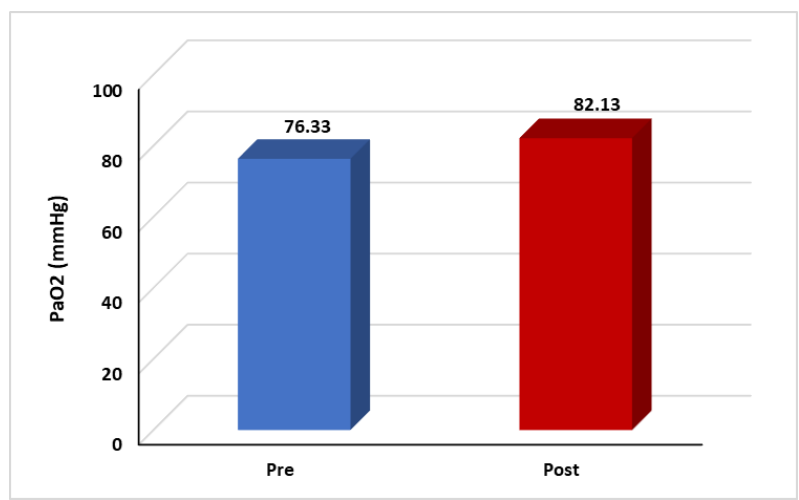

Figure (1): Pre and post treatment mean values of $\mathrm{PaO} 2$

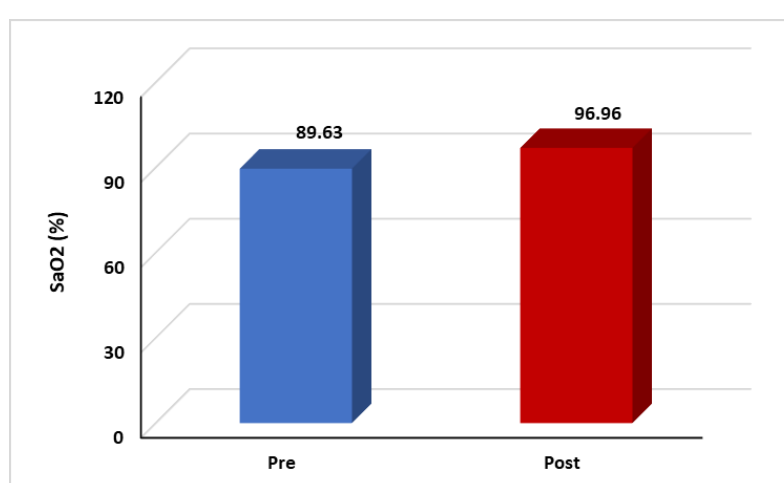

Figure (2): Pre and post treatment mean values of $\mathrm{SaO} 2$ 


\section{DISCUSSION}

This study was conducted to evaluate the effect of chest physiotherapy on pao2 and sao2. There were an increase in $\mathrm{PaO} 2$ and $\mathrm{SaO} 2$.

Zeyu et al. ${ }^{\left({ }^{(10)}\right.}$ investigated the clinical effect of the chest physiotherapy for the postoperative sputum excretion. After chest physiotherapy, the increase of $\mathrm{PaO} 2$ was significant higher than before after three days. Farahat et al., investigated the response of mechanically ventilated to chest physical therapy, there was significant increase in $\mathrm{PaO} 2$ after chest physical therapy (positioning, percussion, vibration and suction.) in the study group ${ }^{(11)}$. Zeng et $\boldsymbol{a l} .{ }^{(\mathbf{1 2})}$ concluded that chest physical therapy decrease the incidence of VAP and increase in $\mathrm{PaO} 2$ in his study group who received comprehensive chest physical therapy.

Chen et al. ${ }^{(13)}$ found that $\mathrm{SaO} 2$ was significantly increased after chest physical ventilated to chest physical therapy, there was significant increase in $\mathrm{SaO} 2$ after chest physical therapy (positioning, percussion, vibration and suction.) in the study group. Zeyu et al $^{(\mathbf{1 0 )}}$ concluded that $\mathrm{SaO} 2$ was significant higher than before after chest physical therapy in the study group.

Paratz et al. ${ }^{(14)}$ demonstrated that there was a decrease in Pao2 after manual hyperinflation in patient with acute intrapulmonary lung injuries.This may be as a result of the candidates were having acute intrapulmonary lung injuries who were excluded from this study, besides applying manual hyperinflation only. Berny et al. ${ }^{(15)}$ demonstrated that a slight decrease in partial pressure of arterial oxygen was observed in his study group following mobilization in ICU, this result may differs from this current study used a comprehensive chest physical therapy program was added including percussion, vibration, manual hyperinflation and positioning besides, limb exercises.

Monica et al. ${ }^{(16)}$ demonstrated no increase in $\mathrm{SaO} 2$ in a prospective, interventional study $\mathrm{A}$ respiratory physiotherapy was initiated, twice a day, to a randomized group of mechanical ventilated patients This disagreement resulted from smaller sample size than used in this current study.

\section{CONCLUSION}

The results support the importance of adding chest physiotherapy program to early MV patients as it increases PAO2, SAO2, decreases complications in patients undergoing $\mathrm{MV}$, decrease ICU duration, ICU related psychological disorders and decrease healthcare costs.

\section{REFERENCES}

1. Reis $M$ and Jegers D (2012): Monitoring costs in the ICU: a search for a pertinent methodology. ActaanaesthesiologicaS candinavica, 56(9): 1104-13.

2. Shrestha R, Dahal R, Mishra S et al. (2013): Ventilator Associated Pneumonia in Tertiary Care Hospital, Journal of Institute of Medicine, 35:3-8.

3. Renu B and Pattanshetty G (2010): Effect of multimodality chest physiotherapy in prevention of ventilator-associated pneumonia: a randomized clinical trial. Indian J Crit Care Med., 14:70-76.

4. Chen Y, Wu L, Mu P, et al. (2009): Using Chest Vibration Nursing Intervention to Improve Expectoration of Airway Secretions and Prevent Lung Collapse in Ventilated ICU Patients. JCMA., 72: 316-322.

5. Nowobilski R, Wloch T, Plaszewski M et al. (2010): Efficacy of physical therapy methods in airway clearance in patients with chronic obstructive pulmonary disease. Pol Arch Med Wewn., 120 (11): 468-478.

6. Denehy $L$ and Berney $S$ (2006): Physiotherapy in the intensive care unit. Physical Therapy Review, 11:49-56.

7. Partsch H (2014): Bed rest versus ambulation in the initial treatment of patients with proximal deep vein thrombosis. Curr Opin Pulm Med., 8:389-393.

8. Chang AT, Boots R, Hodges PW et al. (2004): Standing with assistance of a tilt table in intensive care: a survey of Australian physiotherapy practice. Aust J Physiotherapy, 50:51-54.

9. Gosselink R, Bott J and Johnson M (2008): Physiotherapy for adult patients with critical illness: recommendations of the European Respiratory Society and European Society of Intensive Care Medicine Task Force on Physiotherapy for Critically Ill Patients. Intensive Care Med., 34(7):1188-99.

10. Zeyu Q, Hongjing $L$ and Xueli $Z$ (2016): Observation on Efficacy of Chest Physiotherapy for the Postoperative Sputum Excretion in Lung Transplantation Patients, chest Journal,149(4):599A. 
11. Farahat L, Rahmy F, Mohamed G et al. (2016): Response of mechanically ventilated patients to bronchial hygiene.P:4755-4756. http://www.lib.pt.cu.edu.eg/data\%20Cardiopul monary\%20master\%202016.

12. Zeng M, Yuan $G$ and Zhen $Z$ (2017): Chest Pulmonary Physiotherapy in Patients with Mechanical Ventilation. Chinese Journal of Critical Care Medicine, 29(5): 403-406.

13. Chen X, Ma $P$ and Li $P$ (1996): The effect of early chest physiotherapy on blood gas and circulatory function in old patients after thoracotomy. Chinese journal of nursing, 31(2):70-2.

14. Paratz J, Jeffrey L and Mary M (2002): Effect of Manual Hyperinflation on Hemodynamics, Gas Exchange, and Respiratory Mechanics in Ventilated Patients, Journal of Intensive Care Med., 17: 317.
15. Berney S, Denehy L and Pretto J (2004): Head-down tilt and manual hyperinflation enhance sputum clearance in patients who are intubated and ventilated. Aust J Physiotherpy,50:9-14.

16. Monica $C$, Oana $L$ and Ruxandra $C$ (2014): The Benefits of the Respiratory Physiotherapy Program of the Intensive Care Unit's Mechanical Ventilated Patients. Chest journal of American college of chest physicians, 145(3):191A. 